\title{
Revascularization approaches in patients with radiation-induced carotid stenosis: an updated systematic review and meta-analysis
}

\author{
Andreas Tzoumas', Dimitrios Xenos'1, Stefanos Giannopoulos², Marios Sagris³, Damianos G Kokkinidis4, \\ Christos Bakoyiannis ${ }^{5}$, Dimitrios Schizas ${ }^{5}$
}

\author{
'Aristotle University of Thessaloniki, Thessaloniki, Greece \\ 2Division of Cardiology, Rocky Mountain Regional VA Medical Center, University of Colorado, Denver, CO, United States \\ ${ }^{3}$ General Hospital of Nikaia, Piraeus, Athens, Greece \\ ${ }^{4}$ Department of Medicine, Jacobi Medical Center, Albert Einstein College of Medicine New York, NY, United States \\ ${ }^{5} 1^{\text {st }}$ Department of Surgery, National and Kapodistrian University of Athens, Laikon General Hospital, Athens, Greece
}

\author{
Correspondence to: \\ Stefanos Giannopoulos, MD \\ Division of Cardiology, \\ Rocky Mountain Regional \\ VA Medical Center, \\ University of Colorado, \\ Denver, \\ 1700 N Wheeling St, Aurora, \\ CO 80045, USA, \\ phone: (303) 399-8020, \\ e-mail: \\ stefanosgiannopoulosmed@ \\ gmail.com \\ Copyright by the \\ Author(s), 2021 \\ Kardiol Pol. 2021; \\ 79 (6): 645-653; \\ DOI: 10.33963/KP.15956 \\ Received: \\ November 27, 2020 \\ Revision accepted: \\ April 9, 2021 \\ Published online: \\ April 16, 2021
}

\begin{abstract}
A B S TR A C T
Background: lonizing radiation remains a well-known risk factor of carotid artery stenosis. The survival rates of head and neck cancer patients undergoing radiotherapy have risen owing to medical advancements in the field. As a consequence, the incidence of carotid artery stenosis in these high-risk patients has increased.

Aims: In this study we sought to compare the outcomes of carotid endarterectomy (CEA) vs carotid artery stenting (CAS) for radiation-induced carotid artery stenosis.

Methods: This study was performed according to the Preferred Reporting Items for Systematic reviews and Meta-Analyses guidelines. Eligible studies were identified through a comprehensive search of PubMed, Scopus and Cochrane Central until July 2020. A random-effects model meta-analysis was conducted, and odds ratios (ORs) were calculated. The I-square statistic was used to assess for heterogeneity.

Results: Seven studies and 201 patients were included. Periprocedural stroke, myocardial infarction (MI), and death rates were similar between the two revascularization approaches. However, the risk for cranial nerve $(\mathrm{CN})$ injury was higher in the CEA group (OR, 7.40; $\left.95 \% \mathrm{Cl}, 1.58-34.59 ; \mathrm{I}^{2}=0 \%\right)$. Analysis revealed no significant difference in terms of long-term mortality $\left(\mathrm{OR}, 0.41 ; 95 \% \mathrm{Cl}, 0.14-1.16 ; \mathrm{I}^{2}=0 \%\right)$ and restenosis rates $\left(\mathrm{OR}, 0.69 ; 95 \% \mathrm{Cl}, 0.29-1.66 ; \mathrm{I}^{2}=0 \%\right)$ between $\mathrm{CEA}$ and $\mathrm{CAS}$ after a mean follow-up of 40.5 months.
\end{abstract}

Conclusions: CAS and CEA appear to have a similar safety and efficacy profile in patients with radiation-induced carotid artery stenosis. Patients treated with CEA have a higher risk for periprocedural CN injuries. Future prospective studies are warranted to validate these results.

Key words: carotid stenosis, carotid artery stenting, carotid endarterectomy, endarterectomy, radiation

Kardiol Pol 2021; 79, 6: 645-653

\section{INTRODUCTION}

Carotid artery stenting (CAS) is a less invasive alternative approach to carotid endarterectomy (CEA) [1]. Currently, CEA remains the gold standard for treatment of both symptomatic and asymptomatic carotid atherosclerotic disease, whereas CAS is currently reserved for patients with high surgical risk, including those with post-radiation stenosis [2-5]. Proposed mechanisms for post-radiation carotid stenosis include de novo atherosclerotic lesion development or progression of existing plaques [6, 7]. These atherogenic properties of ionizing radiation have been attributed to pro-inflammatory reactions within the arterial wall that weaken endothelial cells barrier, leading to inflammatory cell recruitment, accumulation and eventually plaque formation $[8,9]$.

Significant carotid stenosis can cause devastating neurological complications, including disabling stroke and transient ischemic attacks (TIA) [9]. Considering the increasing survival rates of patients who undergo radiotherapy for head and neck cancer, the incidence of radiation induced 
WHAT'S NEW?

Radiation-induced carotid stenosis is associated with an increased stroke risk and it is a challenging clinical entity. Carotid endarterectomy (CEA) and carotid artery stenting (CAS) are the two revascularization approaches. Prior work suggested that performing CEA in patients with radiation-induced carotid stenosis might be associated with a lower long-term mortality. The present study, including larger population, did not identify a statistically significant difference in the odds of long-term mortality between patients treated with CEA vs CAS, and confirmed a higher rate of cranial nerve injury with CEA. In addition, we now provide a subgroup analysis based on embolic protection device utilization along with suggestions for the design of future studies.

carotid artery stenosis has risen [10]. The time period from radiation exposure to the development of atherosclerotic carotid lesions causing significant stenosis varies across the literature $[6,11]$, with a recent systematic review suggesting that the yearly incidence of carotid stenosis $>50 \%$ increases every year during the first three years after radiation treatment [12]. Interestingly, patients who received radiotherapy for head and neck malignancies are at higher risk for TIAs or strokes compared to patients with carotid stenosis who were not exposed to radiation therapy [13].

However, the optimal revascularization approach for this high-risk population is still debatable. CEA can be challenging to perform in patients with a history of radiation exposure in the neck due to extensive tissue scarring, whereas CAS has been related to poor long-term anatomic outcome and higher restenosis rates [13-15]. The aim of this systematic review and meta-analysis was to compare the safety and efficacy profiles of CEA and CAS for treatment of radiation-induced carotid stenosis.

\section{METHODS}

This systematic review and meta-analysis was performed according to the Preferred Reporting Items for Systematic reviews and Meta-Analyses (PRISMA) guidelines [16]. Literature searches were systematically conducted in PubMed, Scopus, and Cochrane Central by two independent investigators. The following algorithm was utilized for PubMed dataset: ("radiotherapy" OR "irradiation" OR "radiation") AND ("cervical"OR"neck") AND"carotid" AND ("stenosis"OR "atherosclerosis" OR"restenosis") AND ("operation"OR"surgery" OR "surgical" OR "endarterectomy") AND ("stent" OR "stenting"OR"angioplasty" OR"balloon"OR"endovascular" OR"percutaneous"). Any disagreements were resolved with discussion and consensus was settled with the addition of a $3^{\text {rd }}$ independent reviewer. Additionally, the references of the eligible articles were manually reviewed in order to identify potential additional studies.

Studies that fulfilled all the predefined inclusion criteria were eventually included in this meta-analysis. These were: (1) randomized controlled trials (RCT) or observational studies comparing CEA vs CAS for radiation-induced carotid stenosis; (2) studies reporting on relevant clinical outcomes (e.g. restenosis rate, death, stroke, transient ischemic attack, myocardial infarction, cranial nerve injury); (3) studies published up to July 2020. For this systematic review and meta-analysis of study level data no approval by a local institutional review board was required.

\section{Data extraction and risk of bias assessment}

Data extraction was performed by 2 independent investigators (AT, DX), blind to each other. All disagreements were discussed with a $3^{\text {rd }}$ reviewer (SG) until consensus was settled. The incidence of stroke within 30 days was the primary endpoint. Secondary endpoints were TIA, cranial nerve $(\mathrm{CN})$ injuries, myocardial infarction $(\mathrm{MI})$ and death within 30 days, and long-term mortality and carotid artery restenosis. Risk of bias was assessed by 2 investigators with the Robins-I tool for non-randomized studies [17]. Additionally, publication bias was evaluated with the methods of the Egger's test and funnel plots.

\section{Statistical synthesis and analysis}

Odds ratios (ORs) with the corresponding $95 \%$ confidence intervals (Cls) were synthesized for the primary and secondary outcomes. A random-effects model was used to evaluate heterogeneity among studies with the Higgins I-square $\left(I^{2}\right)$ statistic [18]. $I^{2}$ greater than $75 \%$ indicated significant heterogeneity [18]. The main results (i.e. effect size of each study and pooled estimates) were graphically displayed with a forest plot. A $P$-value $<0.05$ was considered significant. The statistical software used was STATA 14.1 (StataCorp, College Station, TX, USA).

\section{RESULTS}

\section{Search results}

Literature search yielded 191 potentially eligible records after duplicates were removed. Fifteen articles were retrieved for full-text evaluation after screening titles and abstracts. Overall, 7 comparative studies satisfied the predetermined search criteria and were included in this meta-analysis [19-25]. The PRISMA flow diagram is illustrated in Figure 1.

\section{Characteristics of the studies and patients}

In total, 201 patients undergoing procedures for radiation induced carotid artery stenosis were included in this study (CEA, $50.2 \%$ [ $n=101 / 201]$ vs CAS, $49.8 \%[n=100 / 201]$ ). The mean weighted long-term follow up was 40.5 months as calculated from studies with available data. The average 


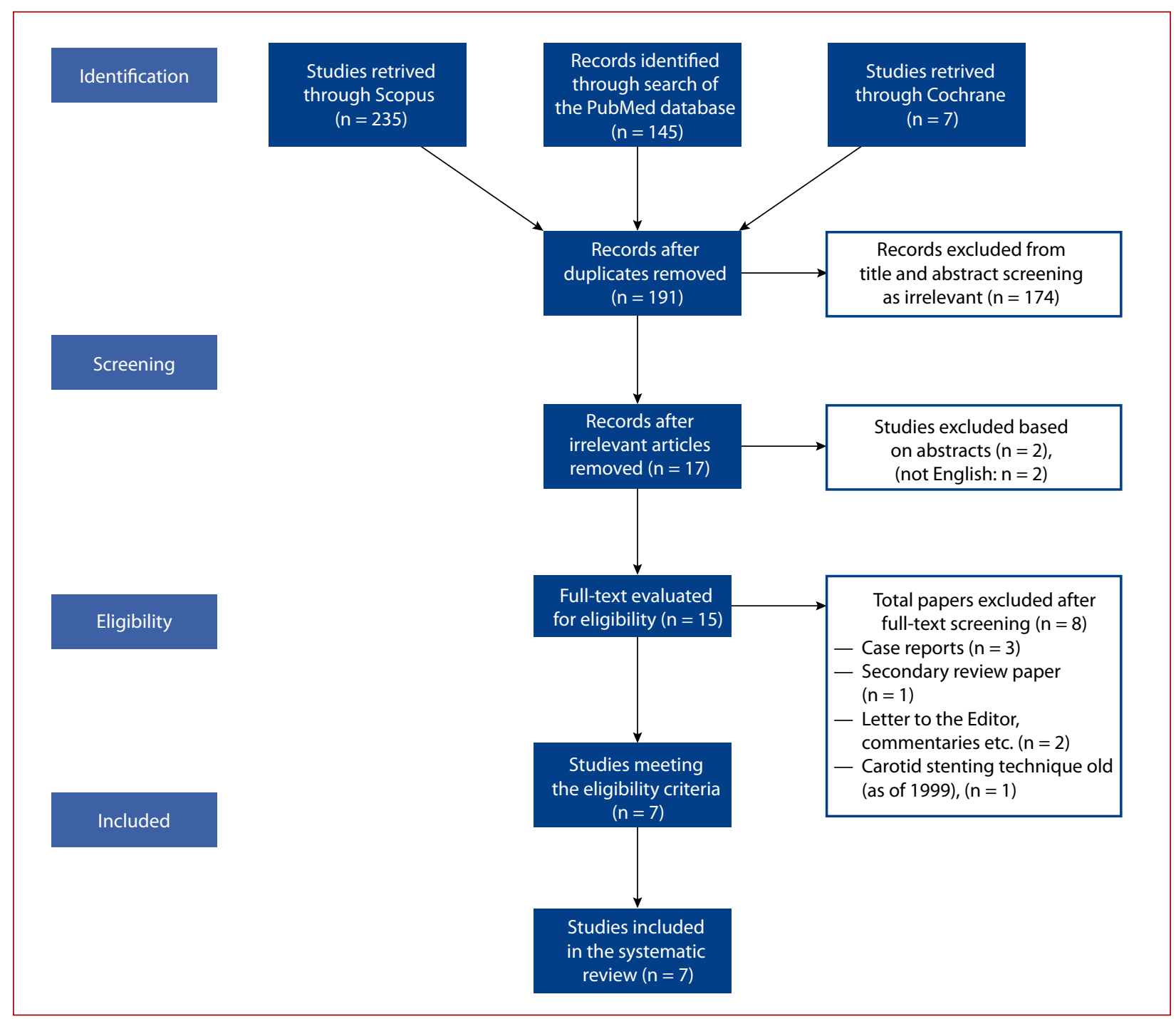

Figure 1. Preferred Reporting Items for Systematic reviews and Meta-Analyses (PRISMA) flow diagram

Table 1. Important patient characteristics

\begin{tabular}{|c|c|c|c|c|c|c|c|c|c|}
\hline Study & Country & $\begin{array}{c}\text { Total } \\
\text { number of } \\
\text { patients, } n\end{array}$ & CEA, $n$ & CAS, $n$ & $\begin{array}{c}\text { Mean age, } \\
\text { years }\end{array}$ & Males, \% & $\begin{array}{c}\text { Symptoma- } \\
\text { tic at baseli- } \\
\text { ne total, \% }\end{array}$ & $\begin{array}{c}\text { Symptoma- } \\
\text { tic at baseli- } \\
\text { ne CEA, \% }\end{array}$ & $\begin{array}{c}\text { Symptomatic } \\
\text { at baseline } \\
\text { CAS, } \%\end{array}$ \\
\hline Carpenter 2018 [22] & USA & 12 & 3 & 9 & 59.6 & NR & 0 & 0 & 0 \\
\hline Gaudry 2017 [24] & France & 43 & 21 & 22 & $\begin{array}{l}\text { CEA: } 66.9 ; \\
\text { CAS: } 68.2\end{array}$ & $\begin{array}{l}\text { CEA: } 81 ; \\
\text { CAS: } 77\end{array}$ & 21 & 28.5 & 13.6 \\
\hline Massoni 2017 [23] & Italy & 12 & 5 & 7 & 71 & 75 & 17 & 0 & 28 \\
\hline Sano 2015 [19] & Japan & 21 & 11 & 10 & 71.6 & 95 & 59 & NR & NR \\
\hline Dorth 2014 [21] & USA & 9 & 3 & 6 & 56 & 78 & 0 & 0 & 0 \\
\hline Tallarita 2011 [20] & USA & 60 & 27 & 33 & 66.5 & 75 & 65 & 74 & 57 \\
\hline Hassen-Kohdja 2004 [25] & International & 44 & 31 & 13 & 64.4 & 51 & 80 & NR & NR \\
\hline
\end{tabular}

Abbreviations: CAS, carotid artery stenting; CEA, carotid endarterectomy; NR, not reported

time interval between carotid artery irradiation and carotid intervention among the individual studies is presented in Supplementary material, Figure S1. No studies with high risk of bias were identified. A detailed assessment of risk of bias can be found in Supplementary material, Table S1. Overall, $19.7 \%(n=34 / 173)$ of the patients had diabetes, 25.4\% $(n=44 / 173)$ had CAD, and 45.5\% $(n=80 / 176)$ had a type of dyslipidemia. Important patient characteristics are summarized in Table 1, while details about comorbidities in the CEA and CAS group are presented in Supplementary material, Table S2.

Carotid artery duplex ultrasound was the most commonly used imaging study to evaluate the plaques' composition and the degree of stenosis. Additionally, computed 
tomography angiography or magnetic resonance angiography were performed or reviewed pre-procedurally in order to identify more specific lesion characteristics, including but not limited to lesion length, degree of calcification, existence of thrombus, or ulceration. The most commonly utilized stents were bare metal stents including the PRECISE stent (Cordis [43.4\%; $n=33 / 76]$ ) and the Wallstent (Boston Scientific [51.3\%; $n=39 / 76]$ ). Carotid artery stenting was mainly performed through femoral access and with local anesthesia. An embolic protection device (EDP) was utilized in $81.6 \%(n=62 / 76)$ of the CAS cases. This lower than expected percentage of EPD utilization was largely driven by the study by Tallarita et al. [20], which reported a $67.5 \%$ EPD utilization rate $(n=25 / 37)$. Three studies $[21,22,25]$ did not report their EPD utilization rate while the rest reported $>90 \%$ utilization.

\section{Early periprocedural outcomes (within 30 days)}

The two carotid revascularization techniques were comparable in terms of periprocedural stroke (CEA, 1.4\%; $\mathrm{n}=1 / 71$ vs CAS, 3.4\%; $\mathrm{n}=2 / 58 ; \mathrm{OR}, 0.64 ; 95 \% \mathrm{Cl}, 0.12-3.37$; $\mathrm{I}^{2}=0 \%$ ) (Figure 2). Of note, the study by Tallarita et al. [20] was not used in the analysis of stroke because of an EPD utilization rate that does not correspond to the current standard of care. In addition, no differences in terms of death (CEA, 1.9\%; $n=2 / 101$ vs CAS, $0 \% ; n=0 / 100 ; O R$, $1.54 ; 95 \% \mathrm{Cl}, 0.34-6.91 ; \mathrm{I}^{2}=0 \%$ ) (Figure 3 ) and myocardial infarction (CEA, 4.6\%; $n=2 / 43$ vs CAS, $0 \% ; n=0 / 50 ; O R, 2.36$; 95\% Cl, 0.30-18.60; $\left.\right|^{2}=0 \%$ ) (Figure 4) were identified. However, patients undergoing CEA had a significantly higher incidence of $\mathrm{CN}$ injuries compared to patients undergoing CAS (CEA, $17.1 \% ; n=11 / 64$ vs CAS, $0 \% ; n=0 / 72 ; O R, 7.40$; $95 \% \mathrm{Cl}, 1.58-34.59 ; I^{2}=0 \%$ ) (Figure 5). The most common
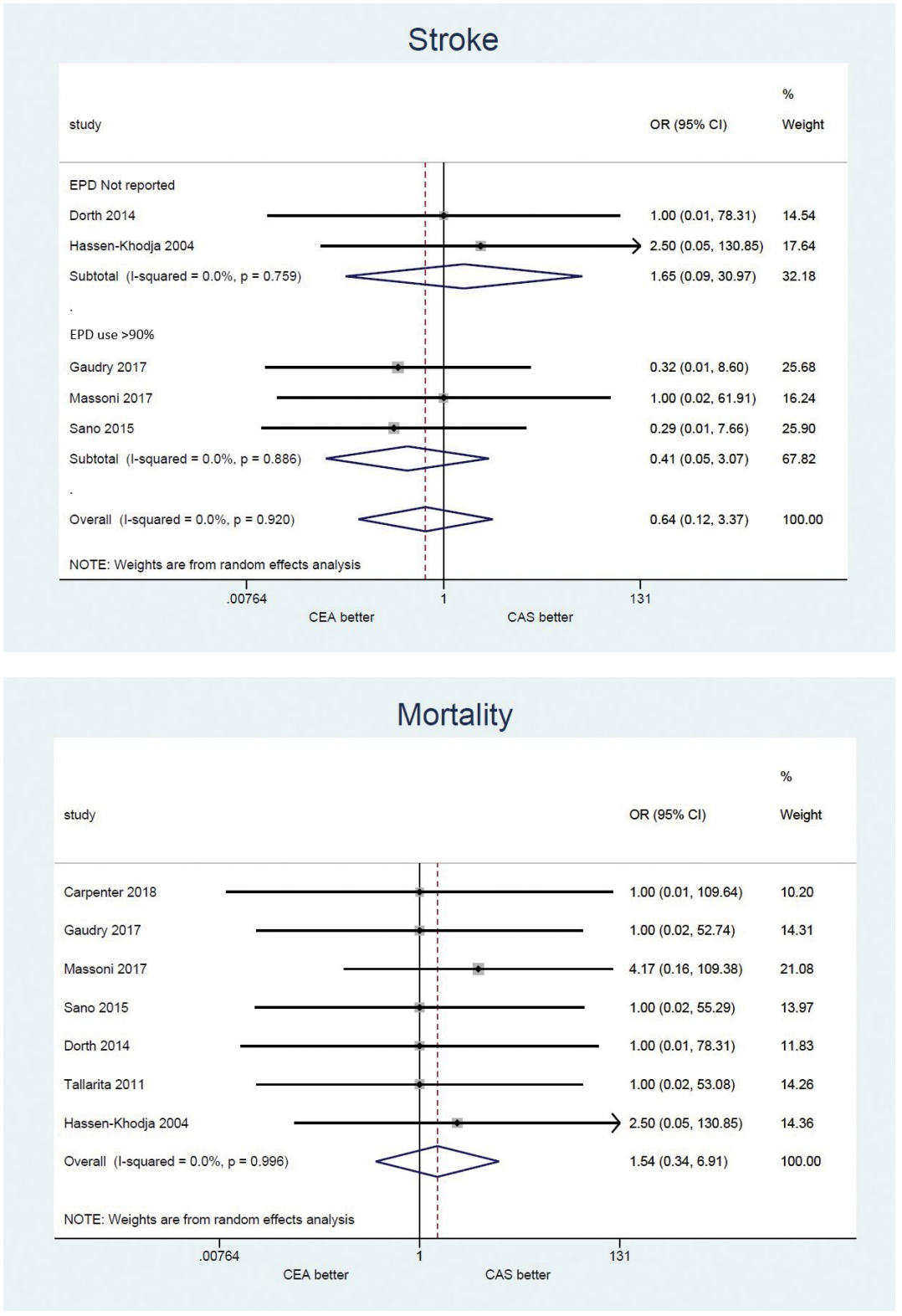

Figure 2. Comparison of 30-day stroke between carotid endarterectomy (CEA) and carotid artery stenting (CAS)
Figure 3. Comparison of 30-day mortality between carotid endarterectomy (CEA) and carotid artery stenting (CAS) 

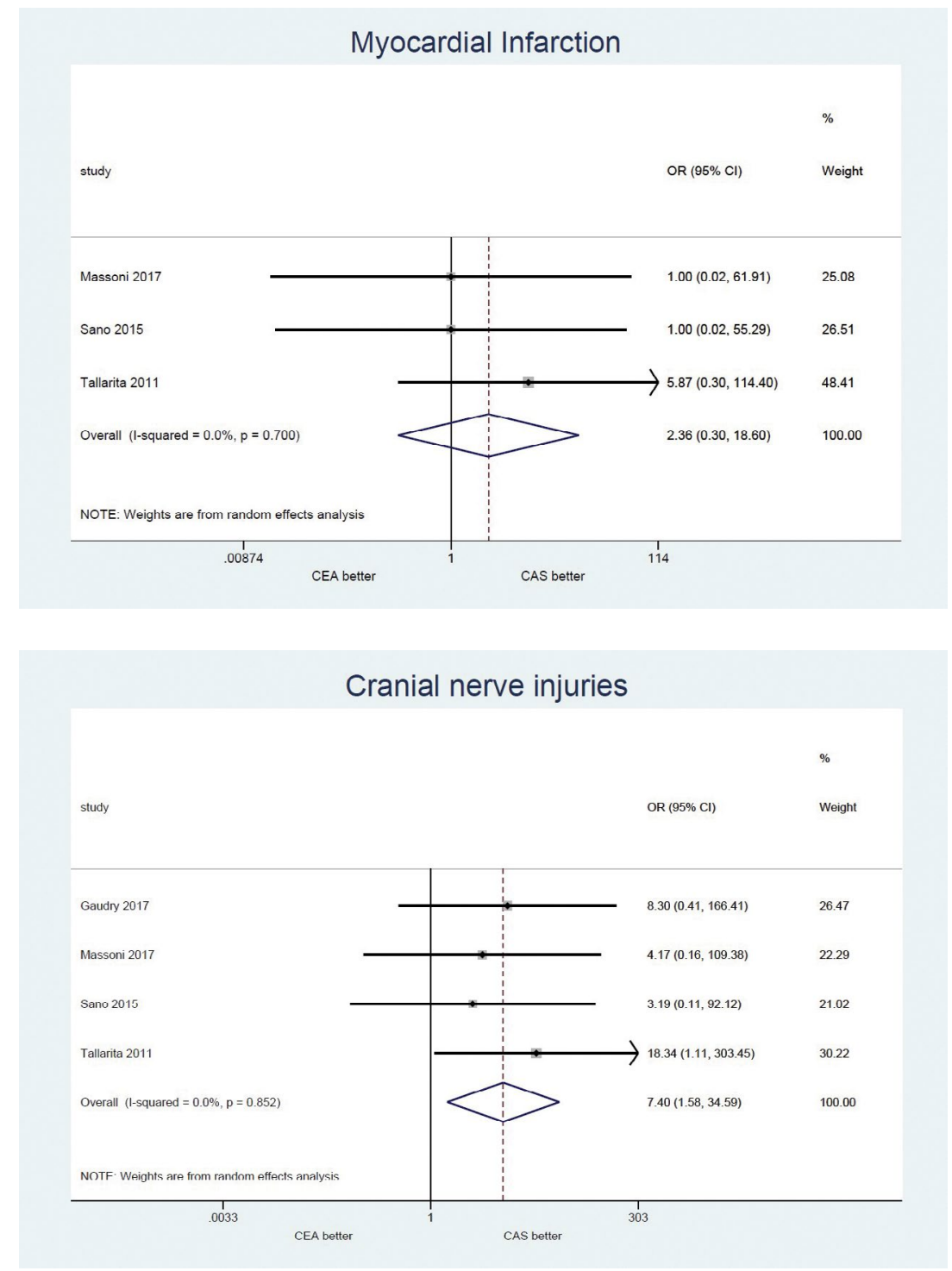

Figure 4. Comparison of 30-day myocardial infarction between carotid endarterectomy (CEA) and carotid artery stenting (CAS)
Figure 5. Comparison of cranial nerve injuries between carotid endarterectomy (CEA) and carotid artery stenting (CAS) injuries affected the hypoglossal and vagus nerves. Two CN injuries were reported to cause permanent deficits. There was no obvious asymmetry in the funnel plots of all early periprocedural outcomes, which were validated by nonsignificant results following the Egger's test (stroke: $P=0.10$; MI: $P=0.06$; death: $P=0.06 ; \mathrm{CNI}: P=0.07$ ) (Supplementary material, Figure S2).

\section{Late outcomes}

Long-term all-cause mortality (40.5 months average) was similar between the CEA and CAS groups (CEA, $7.1 \% ; n=5 / 70$ vs CAS, $17.2 \% ; n=15 / 87 ; O R, 0.41 ; 95 \% \mathrm{Cl}$, $0.14-1.16 ; 1^{2}=0 \%$ ) (Figure 6). Similarly, no difference was detected in the incidence of carotid artery restenosis among patients undergoing CEA vs CAS (CEA, 10.9\%; $n=10 / 101$ vs CAS, $17 \% ; n=17 / 100 ;$ OR, 0.69; 95\% Cl, 0.29-1.66; $\left.I^{2}=0 \%\right)$ (Figure 7). No evidence of publication bias was found for long-term outcomes based on the Egger's test (long-term all-cause mortality: $P=0.14$; restenosis: $P=0.53$ ) and funnel plots (Supplementary material, Figure S2).

\section{Subgroup analysis}

A subgroup analysis was performed for periprocedural stroke by pooling studies that have utilized $>90 \%$ EPD use and those studies that have not reported any EPD utilization rate. Neither of the two subgroups showed any significant difference in terms of stroke (EPD not reported; OR, 1.65 [0.09-30.97] and EPD >90\%; OR, 0.41 [0.05-3.07]) (Figure 2).

\section{DISCUSSION}

This was a systematic review and meta-analysis of seven studies comparing CEA vs CAS for the treatment of carotid stenosis associated with radiotherapy for head and neck cancer. In a previously published meta-analysis CEA yielded a significantly reduced risk of all-cause long-term mortality [4]. In the present study, the long-term mortality difference between the groups was not detected; this result could be attributed to the larger sample size of this study. In addition, we showed that patients undergoing CEA were at an increased risk for periprocedural $\mathrm{CN}$ injuries. However, 


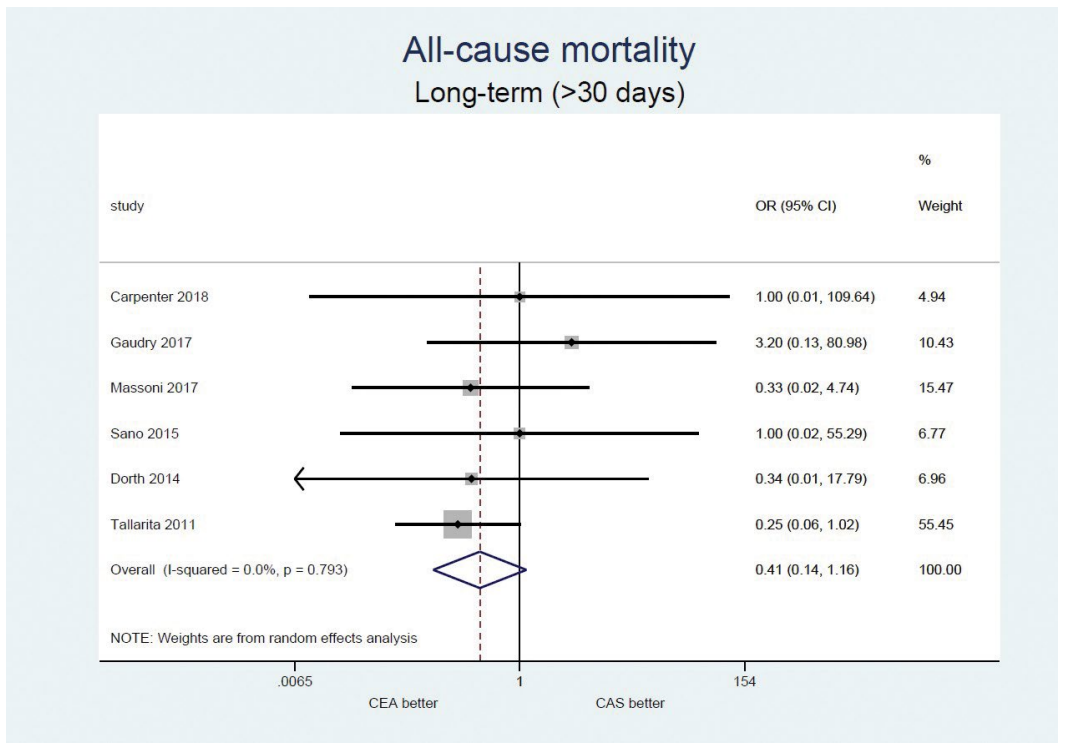

Figure 6. Comparison of late all-cause mortality between carotid endarterectomy (CEA) and carotid artery stenting (CAS)

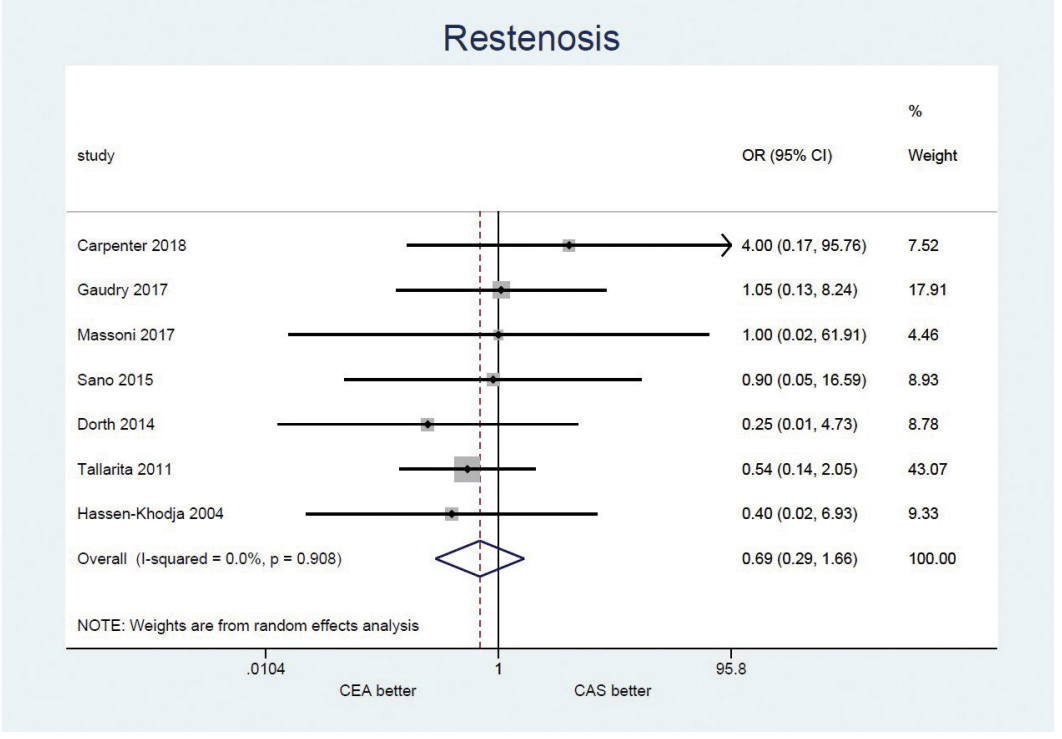

Figure 7. Comparison of late restenosis between carotid endarterectomy (CEA) and carotid artery stenting (CAS) the incidence of periprocedural adverse events including stroke, myocardial infarction and short-term all-cause mortality were similar between the two groups. Additionally, our results demonstrated no differences in terms of late restenosis over an average follow up of 40.5 months between the two groups.

Medical advancements including the use of radiotherapy, chemotherapy, and surgery have led to increased survival rates in patients with head and neck malignancies. This increased survival has inevitably raised the overall incidence of post-radiation carotid artery stenosis which has been estimated to be $2 \%-22 \%$ [23, 26-28]. The development of radiation-induced arterial stenosis has been associated with several different pathogenic mechanisms, including injury and occlusion of the vasa vasorum feeding the arterial wall [29,30], and endothelial cell dysfunction resulting from the effects of ionizing radiation itself [31-33]. Indeed, previous clinical studies have shown that radiation is an independent risk factor for the development of early atherosclerosis [34, 35]. This high-risk patient population often requires carotid revascularization for the prevention of neurologic sequelae, commonly with CEA or CAS. Intervention is challenging, since radiation-induced carotid lesions begin as fibrotic changes within the arterial wall, which convert into more unstable large necrotic lesions over time [19, 32]. This transformation makes them more prone to embolization [36]. Moreover, post-radiation lesions tend to affect more extensive segments of carotid arteries and have multifocal distribution compared to common atherosclerotic lesions; therefore, surgery in irradiated anatomy increases the difficulty of the procedure [37, 38]. Nonetheless, as comparative studies for the treatment of radiation induced carotid artery are sparse, the optimal revascularization approach for this entity is still under investigation. 
Recent progress in the field of endovascular management of carotid stenosis have introduced novel second-generation carotid stents which yielded promising results in preventing distal embolization during CAS ("the cheese-grater effect" with older stents) $[39,40]$. Additionally, current evidence suggests that dual layer embolic prevention stent systems have shown to be safe and effective in reducing stroke risk due to intraprocedural debris dislodgement from the target lesion and during the post-CAS period $[40,41]$. However, the use of EPD can be affected by the operator experience and it has been related with certain complications during deployment or retrieval processes in cases of difficult anatomy and unstable ulcerative plaques [42].

Optimized neuroprotection during CAS with conventional stents may minimize intraprocedural cerebral embolism [43], albeit the problem of early or delayed postprocedural embolism can be better addressed with second generation stents which can maximize plaque coverage and prevent prolapse between the stent struts [44]. This is a great advantage of dual layer stents, since plaque protrusion has been associated with high-risk of ischemic complications during the 30-day post-CAS follow up period [40]. Moreover, proximal occlusion devices using flow arrest or reversal systems shown promising results in preventing post-CAS stroke [45]. Interestingly, the use of a proximal neuroprotection device in combination with new generation mesh stents has been described successfully during the endovascular treatment of challenging cases [46]. Future prospective studies should evaluate the introduction of these novel stents and techniques in the treatment of patients with radiation-induced carotid lesions, which constitute by definition a high-risk subset of patients.

Traditionally CEA has been associated with higher rates of $\mathrm{CN}$ injuries and local wound complications (e.g. infection, poor wound healing) $[11,47]$. Moreover, there is evidence that history of radiotherapy for head and neck malignancies may have an additive effect to this higher risk for $\mathrm{CN}$ deficits owing to fibrotic remodeling in the perivascular soft tissue [48]. Our meta-analysis demonstrated that patients in the CEA group experienced CN injuries more frequently than the patients from the CAS group. However, previous studies are in agreement with the current meta-analysis showing that these cranial nerve deficits are rather transient and of low clinical significance $[11,49]$. Furthermore, as our study did not detect any significant differences in the rates of periprocedural stroke, death, and MI between the two approaches, it could be concluded that both procedures seem to be equally safe in terms of periprocedural complications. It should be noted, however, that even though statistical significance was not reached for periprocedural stroke, its respective absolute incidence rates in CEA and CAS were $1.4 \%$ and $3.4 \%$, which can raise the point of low statistical power to detect this difference. Future prospective cohorts and large registries should be designed to compare the two approaches and validate our results.

Despite the non-inferiority of CAS compared to CEA in terms of periprocedural adverse events, the former has been associated with higher rates of long-term restenosis and poor anatomic outcome in patients with radiation exposure; however, results are inconclusive in the literature. The pooled estimates of our meta-analysis did not show any significant differences in the rates of late restenosis between the two groups. However, it should be noted that the absolute incidence of restenosis in the present study was $9.7 \%$ and $16.3 \%$ in the CEA and CAS groups respectively, which raises the concern of low statistical power to detect this difference. In accordance with our results, a previous systematic review reported a $9.7 \%$ and $18.2 \%$ long-term restenosis rate; however this study was not a meta-analysis and head to head comparisons were not made [50]. Also, a prospective study investigating the long-term outcomes of CAS among patients that received radiotherapy vs patients being at high risk for surgery but without a history of head and neck radiation showed that radiation exposure was associated with lower freedom from restenosis during a mean follow up of 14.4 months; however a comparison between CEA and CAS was not made in that study [14]. In conclusion, current available evidence is insufficient to draw conclusions and thus, prospective studies with standardized follow-up intervals are warranted to investigate and compare restenosis rates in the two groups.

\section{Limitations}

This study was a systematic review and meta-analysis of comparative observational studies. However, there are several limitations that should be acknowledged. EPD use was not consistently reported by all studies and for this reason we conducted a subgroup analysis of stroke based on EPD reporting, which showed no differences. Importantly, however, future studies should always report the use of EPD during CAS as this is considered standard of care and is important information to the reader. Moreover, data regarding radiation dose regimen were inconsistently reported and varied widely among the included studies. The dose of external neck irradiation can affect the severity and extent of radiation-induced vasculopathy and lack of this information might have affected our outcomes. Furthermore, as patient-level data was not available, adjusted OR utilizing patients' comorbidities and procedural characteristics could not be provided. Additionally, data regarding the anti-platelet therapy and statin prescription during follow up were sparse. Furthermore, the data in each treatment arm regarding specific outcomes for symptomatic or asymptomatic carotid disease were inconsistently reported. Lastly, the follow-up intervals were not standardized across the included studies and a consistent definition for restenosis was not provided. 


\section{CONCLUSIONS}

This meta-analysis demonstrated that CEA is associated with higher periprocedural CN injuries compared to CAS, although the periprocedural death, stroke and $\mathrm{MI}$ rates were not different between the two groups. Additionally, no significant differences were detected in terms of late all-cause mortality and restenosis between CEA and CAS. Further prospective studies are needed in order to eliminate bias and identify the optimal therapeutic approach for radiation-induced carotid stenosis.

\section{Article information}

Conflict of interest: None declared.

Open access: This article is available in open access under Creative Common Attribution-Non-Commercial-No Derivatives 4.0 International (CC BY-NC-ND 4.0) license, allowing to download articles and share them with others as long as they credit the authors and the publisher, but without permission to change them in any way or use them commercially. For commercial use, please contact the journal office at kardiologiapolska@ptkardio.pl.

How to cite: Tzoumas A, Xenos D, Giannopoulos S, et al. Revascularization approaches in patients with radiation-induced carotid stenosis: an updated systematic review and meta-analysis. Kardiol Pol. 2021; 79(6): 645-653, doi: 10.33963/KP.15956.

\section{REFERENCES}

1. Magne JL, Pirvu A, Sessa C, et al. Carotid artery revascularisation following neck irradiation: immediate and long-term results. Eur J Vasc Endovasc Surg. 2012; 43(1):4-7, doi: 10.1016/j.ejvs.2011.09.006, indexed in Pubmed: 22001147.

2. Randomised trial of endarterectomy for recently symptomatic carotid stenosis: final results of the MRC European Carotid Surgery Trial (ECST). Lancet. 1998; 351(9113): 1379-1387, indexed in Pubmed: 9593407.

3. Halliday A, Harrison M, Hayter E, et al. Asymptomatic Carotid Surgery Trial (ACST) Collaborative Group. 10-year stroke prevention after successful carotid endarterectomy for asymptomatic stenosis (ACST-1): a multicentre randomised trial. Lancet. 2010;376(9746): 1074-1084, doi: 10.1016/S01406736(10)61197-X, indexed in Pubmed: 20870099.

4. Giannopoulos $S$, Texakalidis $P$, Jonnalagadda AK, et al. Revascularization of radiation-induced carotid artery stenosis with carotid endarterectomy vs. carotid artery stenting: A systematic review and meta-analysis. Cardiovasc Revasc Med. 2018; $19(5$ Pt B): 638-644, doi: 10.1016/j. carrev.2018.01.014, indexed in Pubmed: 29422277.

5. Naylor AR, Ricco JB, de Borst GJ, et al. Editor's choice - management of atherosclerotic carotid and vertebral artery disease: 2017 clinical practice guidelines of the European Society for Vascular Surgery (ESVS). Eur J Vasc Endovasc Surg. 2018; 55(1):3-81, doi: 10.1016/j.ejvs.2017.06.021, indexed in Pubmed: 28851594.

6. Brown PD, Foote RL, McLaughlin MP, et al. A historical prospective cohort study of carotid artery stenosis after radiotherapy for head and neck malignancies. Int J Radiat Oncol Biol Phys. 2005; 63(5): 1361-1367, doi: 10.1016/j.jijrobp.2005.05.046, indexed in Pubmed: 16169673.

7. Stewart FA, Heeneman S, Te Poele J, et al. lonizing radiation accelerates the development of atherosclerotic lesions in ApoE-/- mice and predisposes to an inflammatory plaque phenotype prone to hemorrhage. Am J Pathol. 2006; 168(2):649-658, doi: 10.2353/ajpath.2006.050409, indexed in Pubmed: 16436678.

8. Hoving S, Heeneman S, Gijbels MJJ, et al. Single-dose and fractionated irradiation promote initiation and progression of atherosclerosis and induce an inflammatory plaque phenotype in $\mathrm{ApoE}(-/-)$ mice. Int J Radiat Oncol Biol Phys. 2008; 71(3): 848-857, doi: 10.1016/j.jjrobp.2008.02.031, indexed in Pubmed: 18514779.

9. Katayama I, Hotokezaka Y, Matsuyama T, et al. lonizing radiation induces macrophage foam cell formation and aggregation through JNK-de- pendent activation of CD36 scavenger receptors. Int J Radiat Oncol Biol Phys. 2008; 70(3): 835-846, doi: 10.1016/j.jirobp.2007.10.058, indexed in Pubmed: 18262097.

10. SEER Cancer Statistics Review, 1975-2017. https://seer.cancer. gov/csr/1975_2017/(October 25, 2020).

11. Fokkema $M$, den Hartog $A G$, Bots $M L$, et al. Stenting versus surgery in patients with carotid stenosis after previous cervical radiation therapy: systematic review and meta-analysis. Stroke. 2012; 43(3): 793-801, doi: 10.1161/STROKEAHA.111.633743, indexed in Pubmed: 22207504.

12. Texakalidis P, Giannopoulos S, Tsouknidas I, et al. Prevalence of carotid stenosis following radiotherapy for head and neck cancer: a systematic review and meta-analysis. Head Neck. 2020; 42(5): 1077-1088, doi: 10.1002/hed.26102, indexed in Pubmed: 32048781.

13. Plummer $C$, Henderson RD, O'Sullivan JD, et al. Ischemic stroke and transient ischemic attack after head and neck radiotherapy: a review. Stroke. 2011; 42(9): 2410-2418, doi: 10.1161/STROKEAHA.111.615203, indexed in Pubmed: 21817150.

14. Protack CD, Bakken AM, Saad WE, et al. Radiation arteritis: a contraindication to carotid stenting? J Vasc Surg. 2007; 45(1): 110-117, doi: 10.1016/j. jvs.2006.08.083, indexed in Pubmed: 17210394.

15. Shin SH, Stout CL, Richardson Al, et al. Carotid angioplasty and stenting in anatomically high-risk patients: Safe and durable except for radiation-induced stenosis. JVasc Surg. 2009; 50(4): 762-767; discussion 767-768, doi: 10.1016/j.jvs.2009.04.066, indexed in Pubmed: 19786237.

16. Shamseer L, Moher D, Clarke M, et al. PRISMA-P Group. Preferred reporting items for systematic review and meta-analysis protocols (PRISMA-P) 2015: elaboration and explanation. BMJ. 2015; 350: g7647, doi: 10.1136/bmj. g7647, indexed in Pubmed: 25555855.

17. Sterne JAC, Hernán MA, Reeves $B C$, et al. ROBINS-I: a tool for assessing risk of bias in non-randomised studies of interventions. BMJ. 2016; 355: i4919, doi: 10.1136/bmj.i4919, indexed in Pubmed: 27733354.

18. Higgins JPT, Thompson SG, Deeks JJ, et al. Measuring inconsistency in meta-analyses. BMJ. 2003; 327(7414): 557-560, doi: 10.1136/bmj.327.7414.557, indexed in Pubmed: 12958120.

19. Sano N, Satow T, Maruyama D, et al. Relationship between histologic features and outcomes of carotid revascularization for radiation-induced stenosis. J Vasc Surg. 2015;62(2): 370-377.e1, doi: 10.1016/j.jvs.2015.03.021, indexed in Pubmed: 25937602.

20. Tallarita T, Oderich GS, Lanzino G, et al. Outcomes of carotid artery stenting versus historical surgical controls for radiation-induced carotid stenosis. J Vasc Surg. 2011; 53(3): 629-636.e1-e5, doi: 10.1016/j.jvs.2010.09.056, indexed in Pubmed: 21216558.

21. Dorth JA, Patel PR, Broadwater G, et al. Incidence and risk factors of significant carotid artery stenosis in asymptomatic survivors of head and neck cancer after radiotherapy. Head Neck. 2014; 36(2): 215-219, doi: 10.1002/hed.23280, indexed in Pubmed: 23554082.

22. Carpenter DJ, Mowery YM, Broadwater G, et al. The risk of carotid stenosis in head and neck cancer patients after radiation therapy. Oral Oncol. 2018; 80: 9-15, doi: 10.1016/j.oraloncology.2018.02.021, indexed in Pubmed: 29706194

23. Bianchini Massoni C, Gargiulo M, Pini R, et al. Radiation-induced carotid stenosis: perioperative and late complications of surgical and endovascular treatment. J Cardiovasc Surg (Torino). 2017; 58(5): 680-688, doi: 10.23736/S0021-9509.16.08666-3, indexed in Pubmed: 25779777.

24. Gaudry M, David B, Omnes V, et al. Radiation-induced carotid stenosis: A personnalized approach [article in French]. J Med Vasc. 2017; 42(5): 263-271, doi: 10.1016/j.jdmv.2017.06.001, indexed in Pubmed: 28964385.

25. Hassen-Khodja R, Kieffer E. University Association for Research in Vascular Surgery. Radiotherapy-induced supra-aortic trunk disease: early and long-term results of surgical and endovascular reconstruction. J Vasc Surg. 2004; 40(2): 254-261, doi: 10.1016/j.jvs.2004.04.020, indexed in Pubmed: 15297818.

26. Chang YJ, Chang TC, Lee TH, et al. Predictors of carotid artery stenosis after radiotherapy for head and neck cancers. J Vasc Surg. 2009; 50(2): 280-285, doi: 10.1016/j.jvs.2009.01.033, indexed in Pubmed: 19631860.

27. Steele SR, Martin MJ, Mullenix PS, et al. Focused high-risk population screening for carotid arterial stenosis after radiation therapy for head and neck cancer. Am J Surg. 2004; 187(5): 594-598, doi: 10.1016/j.amjsurg.2004.01.014, indexed in Pubmed: 15135672. 
28. Abayomi OK. Neck irradiation, carotid injury and its consequences. Oral Oncol. 2004; 40(9): 872-878, doi: 10.1016/j.oraloncology.2003.12.005, indexed in Pubmed: 15380164.

29. Powers B, Thames H, Gillette E. Long-term adverse effects of radiation inhibition of restenosis: radiation injury to the aorta and branch arteries in a canine model. Int J Radiat Oncol Biol Phys. 1999; 45(3): 753-759, doi: 10.1016/s0360-3016(99)00219-9.

30. Zidar N, Ferluga D, Hvala A, et al. Contribution to the pathogenesis of radiation-induced injury to large arteries. J Laryngol Otol. 1997; 111(10): 988-990, doi: 10.1017/s0022215100139167, indexed in Pubmed: 9425496.

31. Murros KE, Toole JF. The effect of radiation on carotid arteries. A review article. Arch Neurol. 1989; 46(4):449-455, doi: 10.1001/archneur.1989.00520400109029, indexed in Pubmed: 2650664.

32. Sugihara T, Hattori Y, Yamamoto $Y$, et al. Preferential impairment of nitric oxide-mediated endothelium-dependent relaxation in human cervical arteries after irradiation. Circulation. 1999; 100(6):635-641, doi: 10.1161/01. cir.100.6.635, indexed in Pubmed: 10441101.

33. Halle M, Gabrielsen A, Paulsson-Berne $G$, et al. Sustained inflammation due to nuclear factor-kappa B activation in irradiated human arteries. J Am Coll Cardiol. 2010; 55(12): 1227-1236, doi: 10.1016/j.jacc.2009.10.047, indexed in Pubmed: 20298930.

34. Dorresteijn LDA, Kappelle AC, Scholz NMJ, et al. Increased carotid wall thickening after radiotherapy on the neck. Eur J Cancer. 2005; 41(7): 10261030, doi: 10.1016/j.ejca.2005.01.020, indexed in Pubmed: 15862751.

35. Gujral DM, Chahal N, Senior R, et al. Radiation-induced carotid artery atherosclerosis. Radiother Oncol. 2014; 110(1): 31-38, doi: 10.1016/j. radonc.2013.08.009, indexed in Pubmed: 24044796.

36. Renard R, Davaine JM, Couture T, et al. Surgical repair of radiation-induced carotid stenosis. J Vasc Surg. 2020; 72(3): 959-967, doi: 10.1016/j, jvs.2019.11.034, indexed in Pubmed: 32035779.

37. Thalhammer C, Husmann M, Glanzmann C, et al. Carotid artery disease after head and neck radiotherapy. Vasa. 2015; 44(1): 23-30, doi: 10.1024/0301-1526/a000403, indexed in Pubmed: 25537055.

38. Shichita T, Ogata T, Yasaka $M$, et al. Angiographic characteristics of radiation-induced carotid arterial stenosis. Angiology. 2009; 60(3): 276-282, doi: 10.1177/0003319709335905, indexed in Pubmed: 19497924.

39. Paraskevas KI, Mikhailidis DP, Veith FJ. Mechanisms to explain the poor results of carotid artery stenting (CAS) in symptomatic patients to date and options to improve CAS outcomes. J Vasc Surg. 2010; 52(5): 1367-1375, doi: 10.1016/j.jvs.2010.04.019, indexed in Pubmed: 20638227.

40. Kotsugi M, Takayama K, Myouchin K, et al. Carotid artery stenting: investigation of plaque protrusion incidence and prognosis. JACC CardiovasC Interv. 2017; 10(8): 824-831, doi: 10.1016/j.jcin.2017.01.029, indexed in Pubmed: 28427600.
41. Mazurek A, Borratynska A, Malinowski KP, et al. MicroNET-covered stents for embolic prevention in patients undergoing carotid revascularisation: twelve-month outcomes from the PARADIGM study. Eurolntervention. 2020; 16(11): e950-e952, doi: 10.4244/EIJ-D-19-01014, indexed in Pubmed: 32482614.

42. Maynar M, Baldi S, Rostagno R, et al. Carotid stenting without use of balloon angioplasty and distal protection devices: preliminary experience in 100 cases. AJNR Am J Neuroradiol. 2007; 28(7): 1378-1383, doi: 10.3174/ajnr.A0543, indexed in Pubmed: 17698546.

43. Montorsi P, Caputi L, Galli S, et al. Microembolization during carotid artery stenting in patients with high-risk, lipid-rich plaque. A randomized trial of proximal versus distal cerebral protection. J Am Coll Cardiol. 2011; 58(16): 1656-1663, doi: 10.1016/j.jacc.2011.07.015, indexed in Pubmed: 21982309.

44. Musiałek P, Roubin GS. Commentary: double-layer carotid stents: from the clinical need, through a stent-in-stent strategy, to effective plaque isolation... the journey toward safe carotid revascularization using the endovascular route. J Endovasc Ther. 2019; 26(4): 572-577, doi: 10.1177/1526602819861546, indexed in Pubmed: 31303133.

45. Grunwald IQ, Reith W, Kühn AL, et al. Proximal protection with the Gore PAES can reduce DWI lesion size in high-grade stenosis during carotid stenting. Eurolntervention. 2014; 10(2): 271-276, doi: 10.4244/ElJV10I2A45, indexed in Pubmed: 24531258.

46. Latacz P, Simka M, Popiela T. The use of a proximal protection system, a reperfusion catheter, and new-generation mesh stents in combined endovascular therapy for a long, symptomatic dissection of the right internal carotid artery. Kardiol Pol. 2020; 78(6): 597-598, doi: 10.33963/KP.15305, indexed in Pubmed: 32329318.

47. Sardar $\mathrm{P}$, Chatterjee $\mathrm{S}$, Aronow HD, et al. Carotid artery stenting versus endarterectomy for stroke prevention: a meta-analysis of clinical trials. J Am Coll Cardiol. 2017;69(18):2266-2275, doi: 10.1016/j.jacc.2017.02.053, indexed in Pubmed: 28473130.

48. Derubertis BG, Hynecek RL, Kent KC, et al. Carotid tortuosity in patients with prior cervical radiation: increased technical challenge during carotid stenting. Vasc Endovascular Surg. 2011; 45(7): 619-626, doi: 10.1177/1538574411408745, indexed in Pubmed: 21646237.

49. Kakisis JD, Antonopoulos CN, Mantas G, et al. Cranial nerve injury after carotid endarterectomy: incidence, risk factors, and time trends. Eur J Vasc Endovasc Surg. 2017; 53(3): 320-335, doi: 10.1016/j.ejvs.2016.12.026, indexed in Pubmed: 28117240.

50. Kasivisvanathan V, Thapar A, Davies KJ, et al. Periprocedural outcomes after surgical revascularization and stenting for postradiotherapy carotid stenosis. J Vasc Surg. 2012; 56(4): 1143-1152.e2, doi: 10.1016/j. jvs.2012.04.044, indexed in Pubmed: 22819749. 